\title{
Lightweight Investigation of Extended-Range Electric Vehicle Based on Collision Failure Using Numerical Simulation
}

\author{
Jiangqi Long, ${ }^{1,2}$ Wenhao Huang, ${ }^{1}$ and Wuhu Zhang1 \\ ${ }^{1}$ College of Mechanical \& Electrical Engineering, Wenzhou University, Wenzhou 325035, China \\ ${ }^{2}$ School of Mechanical \& Automotive Engineering, South China University of Technology, Guangzhou 510641, China \\ Correspondence should be addressed to Jiangqi Long; longjiangqi@163.com
}

Received 6 December 2014; Accepted 6 February 2015

Academic Editor: Changjun Zheng

Copyright (c) 2015 Jiangqi Long et al. This is an open access article distributed under the Creative Commons Attribution License, which permits unrestricted use, distribution, and reproduction in any medium, provided the original work is properly cited.

\begin{abstract}
The total weight of Extended-Range Electric Vehicle (E-REV) is too heavy, which affects rear-end collision safety. Using numerical simulation, a lightweight method is designed to reduce E-REV body and key parts weight based on rear-end collision failure analysis. To calculate and optimize the performance of vehicle safety, the simulation model of E-REV rear-end collision safety is built by using finite element analysis. Drive battery pack lightweight design method is analyzed and the bending mode and torsional mode of EREV before and after lightweight are compared to evaluate E-REV rear-end collision safety performance. The simulation results of optimized E-REV safety structure are verified by both numerical simulation and experimental investigation of the entire vehicle crash test.
\end{abstract}

\section{Introduction}

Fuel-efficient and new energy vehicles were being formulated with more severe engine emission standard and fuel consumption standard. But the design of fuel-efficient and new energy vehicles must be secondary development on the basis of traditional fuel vehicle and increase the parts such as power battery and drive motor. So, reducing the auto body weight is important to improve vehicle fuel economy. According to statistics, fuel consumption will be saved from $6 \%$ to $8 \%$ when 10 percent of vehicle weight is reduced. In other words, the fuel consumption per hundred kilometers will be cut down from 0.3 to $0.5 \mathrm{~L}$ and carbon dioxide emission will lessen from 8 to $10 \mathrm{~g}$ when the vehicle weight is reduced $100 \mathrm{~kg}$. Therefore, reducing the vehicle weight is an effective measure for decreasing fuel consumption and emission pollution $[1,2]$.

There are two ways to achieve vehicle body structure lightweight [3]. One is by using light and high strength materials such as aluminum and high strength steel [4]; the other is by designing rational structure to make the parts thinner, hollow, and composite $[5,6]$.

The vehicles safety will be greatly affected as vehicle weight increases largely. So, the chassis performance must be adjusted and the crash performance must be analyzed. According to the car regulations, the new energy vehicles request not only the properties of good fuel economy and emissions but also the vehicle safety close to the traditional fuel cars.

Recently, the research on new energy vehicles has just started and the research results are limited. Most of automobile lightweight achievements mainly focus on traditional fuel vehicles. Therefore, it is necessary to study the analysis of vehicle lightweight technology based on crash safety.

In this paper, an Extended-Range Electric Vehicle (EREV) will be analyzed to satisfy the lightweight design based on rear-crash safety.

\section{The Basic Structure of E-REV}

E-REV is a new pure electric vehicle with Range Extender (RE). When the battery power is enough, E-REV will move under the pure electric mode; if not enough, RE will work to charge the batteries or direct drive motor work $[7,8]$. The rear floor structure of E-REV is shown in Figure 1.

The prototype vehicle is a mass-produced vehicle, so the structure of vehicle cannot be altered too much and can 


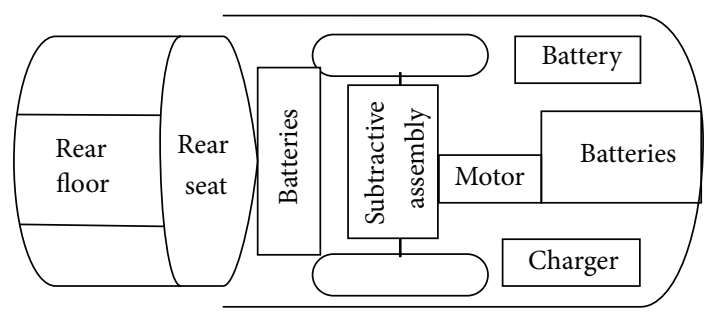

FIGURE 1: The rear floor structure of E-REV.

only transform in a small area. Compared with the prototype vehicle, the E-REV weight is increased about $270 \mathrm{~kg}$.

The rear axle and rear floor structure of E-REV changed a lot (shown in Figure 1). In engine compartment, original engine is replaced by $\mathrm{RE}$, and motor and poor fuel reduction are installed on rear axle. The battery pack 1 is added between the rear seats with car trunk. The battery pack 2 was placed on the location of the spare tire. The charger and the $12 \mathrm{v}$ leadacid battery were placed on both sides of car trunk; therefore, the drive motor and power battery boxes could bring great influence to the safety of vehicle rear-crash.

As E-REV before lightweight has passed standards GB/T 15083-2006 (seat and seat fastness equipment and pillow intension requirements and test method) [9], GB/T 197512005 (hybrid electric vehicles safety specification) [10], and GB 20072 (the requirements of fuel system safety in the event of rear-end collision for passenger car test) [11], the simulation results agreed well with the test results. Therefore, the same simulation method can be used to analyse lightweight design of E-REV.

\section{The Finite Element Analysis of E-REV before Lightweight}

According to standard GB 20072, the simulation model of E-REV is built and analyzed. The pre- and postprocessing of FEM choose OASYS and solver chooses LS-DYNA. The simulation parameters are based on the prototype vehicle test data. The material of vehicle body and fixed frame both choose steel, modulus of elasticity is $211 \mathrm{GPa}$, density is $7.85 \mathrm{~g} / \mathrm{cm}^{3}$, Poisson's ratio is 0.4 , and yield limit is $340 \mathrm{MPa}$. The simulation model has 699924 elements, 718797 nodes, and 5799 welding spots [12].

\subsection{The Finite Element Analysis Result of E-REV before} Lightweight. Table 1 shows the finite element analysis results of E-REV body before lightweight with dormer, front, and back windshield glasses and front subframe. As shown in Table 1, the bending mode and torsional mode of the E-REV body meet with the design requirement. But the first torsional mode simulation result is close to the lower limits of target value. So it needs to improve.

The data of Table 2 come from prototype vehicle. As shown in Table 2, the BIW rigidity before lightweight is far greater than target value and satisfies the design requirements. Therefore, the NVH performance of E-REV after lightweight design must be similar to the prototype vehicle.
TABLE 1: The mode simulation results of E-REV before weight loss of main parts.

\begin{tabular}{lcc}
\hline & First bending mode $(\mathrm{Hz})$ & First torsional mode $(\mathrm{Hz})$ \\
\hline E-REV & 44.5 & 38.3 \\
Target value & & $\geq 35$ \\
\hline
\end{tabular}

TABLE 2: The vehicle rigidity simulation results of E-REV before weight loss of main parts.

\begin{tabular}{lcc}
\hline & BIW & $\begin{array}{c}\text { BIW + front and } \\
\text { back windshield }+ \\
\text { front subframe }\end{array}$ \\
\hline $\begin{array}{l}\text { Bending rigidity } \\
(\mathrm{N} / \mathrm{mm})\end{array}$ & 28541 & 28302 \\
$\begin{array}{l}\text { Target value } \\
\begin{array}{l}\text { Torsional } \\
\text { rigidity }\left(\mathrm{Nm} /{ }^{\circ}\right)\end{array}\end{array}$ & 15232 & $\geq 8700$ \\
Target value & $\geq 10500$ & 19587 \\
\hline
\end{tabular}

3.2. The Result of Rear-End Collision Simulation of E-REV before Lightweight. The simulation model is imported in the FEM software and is simulated. The processor chooses OASYS while solver chooses LS-DYNA. The result of rearend collision simulation of E-REV is shown in Figure 2.

The simulation result shows that the right and left back stringer and subframe were greatly crumpled, and the crumple pattern is conductive to absorb the crash energy. The subframe moved backward and extruded fuel tank. The maximal stress of subframe is $244.6 \mathrm{MPa}$. The drive motor and subtractive assembly have a collision with fuel tank, but the collision force is not big. The maximal plastic deformation of fuel tank is $21 \mathrm{~mm}$.

3.3. The Rear-End Collision Simulation Results of E-REV Battery Pack before Lightweight. As the E-REV rear bumper is impacted directly in the process of the rear-end collision test, the battery pack and its fixed support are greatly impacted and the battery pack fixed support needs to bear the high extruding strength. So the special structure must be designed to protect batteries when the battery pack can turn or move along the direction of the collision slope to provide enough space for absorbing crash energy in rear-crash test. At the same time, it can prevent the battery electrolyte leak as battery pack mutual extrusion or other potential risks. The simulation results are shown in Figure 3.

As shown in Figure 3, battery pack 1 can rotate some angle around the upper fixed point and give some deformation space to battery pack 2 . The design scheme avoids two battery packs' mutual extruding and protects two battery packs.

The lower part of battery pack 1 is shocked largely and middle battery module deforms seriously. The result is present in Figure 4(a). The front left battery module bracket is severely crushed and severely deforms in rear-end collision simulation. The simulation result is present in Figure 4(b). The maximal deformation is over $30 \mathrm{~mm}$. Battery pack 2 deforms apparently but the rear battery module deforms relatively smaller. Judging from the analysis results, it could 


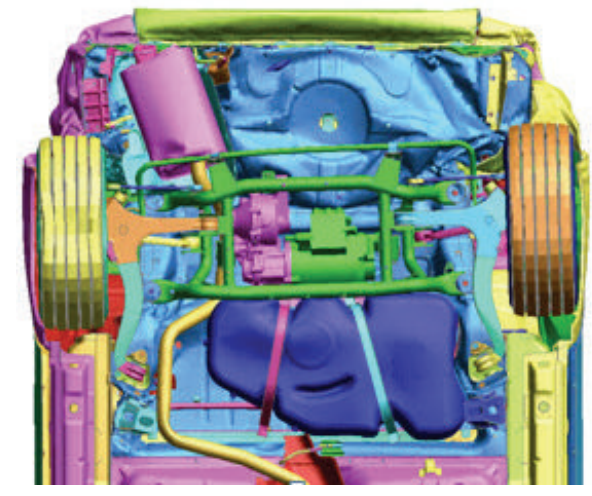

FIGURE 2: The rear-end collision simulation of E-REV.

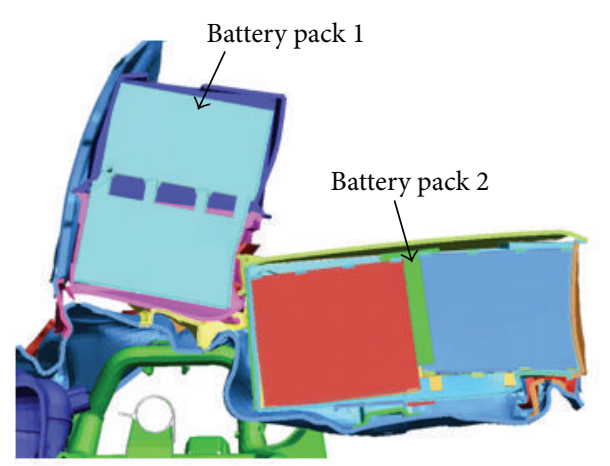

FIgURE 3: The impact simulation results of E-REV drive battery under rear-end collision test.

pass the requirement of standards GB 20072 and GB/T 19751. The deformation of two battery packs must be as small as possible. Otherwise, the risk of collision exists [13].

In rear-end collision test, the car trunk and low voltage battery on car trunk right stringer fixation were serious extrusion deformation; it may lead to battery electrode direct touch with vehicle body sheet metal. The potential risks require the special attention during lightweight design.

In conclusion, although the fuel tank does not leak and can pass the rear-end collision test, some risks still exist.

\section{E-REV Lightweight Design Program}

The lightweight design program of E-REV should consider not only the weight and vehicle performance but also the suitable price of parts. According to the optimization target of the lightweight design, all effective factors should be considered. So the problem of selecting lightweight design program is a complex multiobjective optimization problem. Look for the optimization values after considering all factors; then the lightweight design program could be gained.

4.1. Sensitivity Analysis of Vehicle Body Parts. In order to simplify the process, select the bending and torsional mode as the modes constraint condition and the vehicle body bending
TABLE 3: The mode sensitivity of main parts thickness.

\begin{tabular}{lccc}
\hline $\begin{array}{l}\text { Variable } \\
\text { number }\end{array}$ & $\begin{array}{c}\text { Thickness } \\
(\mathrm{t} / \mathrm{mm})\end{array}$ & $\begin{array}{c}\text { Torsional } \\
\text { sensitivity } \\
\left(\mathrm{Hz} \cdot \mathrm{m}^{-1}\right)\end{array}$ & $\begin{array}{c}\text { Bending } \\
\text { sensitivity } \\
\left(\mathrm{Hz} \cdot \mathrm{m}^{-1}\right)\end{array}$ \\
\hline 02 & 1.5 & -0.0065 & -0.0057 \\
03 & 1.5 & -0.0017 & -0.0023 \\
07 & 1.5 & -38.17 & 84.16 \\
09 & 1.75 & 16.58 & 34.58 \\
12 & 0.8 & 229.4 & -843.7 \\
15 & 0.8 & -1563 & -373.7 \\
17 & 0.8 & 5198 & 4318 \\
18 & 1.2 & -687.3 & 1192 \\
22 & 1.5 & -1125 & 237.8 \\
26 & 2.0 & -1008 & 32.46 \\
29 & 1.0 & -754.1 & 398.7 \\
35 & 2.0 & -0.0018 & 0.0016 \\
47 & 1.5 & -0.0024 & 0.0031 \\
55 & 1.5 & -0.0026 & 0.0018 \\
57 & 1.5 & -0.0040 & -0.0033 \\
\hline
\end{tabular}

and torsional rigidity as rigidity constraint condition for optimization design. Then the sensitivity relationship between the thickness of the main vehicle body parts and torsional and bending sensitivity is obtained as shown in Table 3 .

In Table 3, the sensitivity of thickness of number 15 (left stringer), number 17 (vehicle side panels), and number 22 (right stringer) is high for the first mode of the E-REV body. From the prototype vehicle test data, the vehicle front floor, middle floor, rear floor, rear stringer, threshold, and reinforced plate of the central channel constitute the vehicle basic torsional loading area; the area and its reinforced lateral confining structure components are effective to improve the vehicle first torsional mode. Therefore, it is important to avoid weak parts which are sensitive to the vehicle first mode and the main lightweight design targets should focus on parts which are insensitive to vehicle mode.

4.2. Optimization Design of E-REV. According to the optimization design, the weight of the key parts can be reduced effectively by using the strong and light materials.

Suppose the optimization target $P=\left\{\begin{array}{lllll}P_{1} & P_{2} & \cdots & P_{m}\end{array}\right\}$, alternatives $A=\left\{\begin{array}{llll}A_{1} & A_{2} & \cdots & A_{n}\end{array}\right\}$, weight of every subgoal $W=\left\{\begin{array}{lllll}w_{1} & w_{2} & \cdots & w_{n}\end{array}\right\}^{T}$, and multitarget optimization target matrix and the standardization matrix are defined as

$$
a=\begin{gathered}
A_{1} \\
A_{2} \\
\vdots \\
A_{n}
\end{gathered}\left[\begin{array}{cccc}
a_{11} & a_{12} & \cdots & a_{1 m} \\
a_{21} & a_{22} & \cdots & a_{2 m} \\
\vdots & \vdots & \vdots & \vdots \\
a_{n 1} & a_{n 2} & \cdots & a_{n n}
\end{array}\right]\left[\begin{array}{c}
w_{1} \\
w_{2} \\
\vdots \\
w_{m}
\end{array}\right],
$$




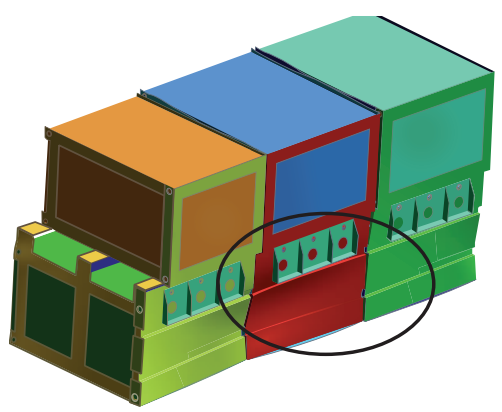

(a) Deformation of battery pack 1

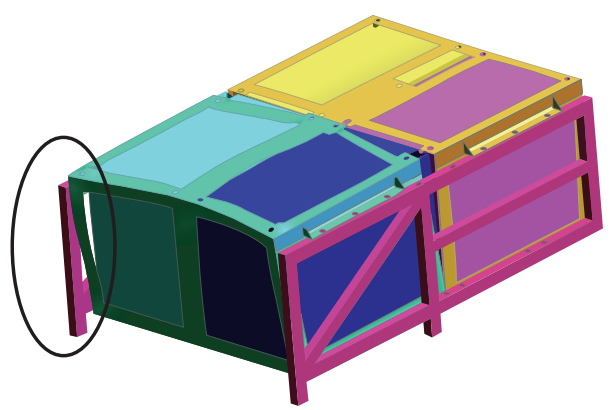

(b) Deformation of battery pack 2

FIGURE 4: The rear-end collision simulation of battery pack 1 and battery pack 2 .

$$
C=\begin{gathered}
A_{1} \\
A_{2} \\
\vdots \\
A_{n}
\end{gathered}\left[\begin{array}{cccc}
c_{11} & c_{12} & \cdots & c_{1 m} \\
c_{21} & c_{22} & \cdots & c_{2 m} \\
\vdots & \vdots & \vdots & \vdots \\
c_{n 1} & c_{n 2} & \cdots & c_{n n}
\end{array}\right]\left[\begin{array}{c}
w_{1} \\
w_{2} \\
\vdots \\
w_{m}
\end{array}\right]
$$

where $C$ is the standardization target matrix after dimension magnitude target value is standardized, $c_{i j}=a_{i j} / \sqrt{\left(\sum_{k=1}^{n} a_{i j}^{2}\right)}$, $i=1,2, \ldots, n, j=1,2, \ldots, m$, and $a_{i j}$ is the parameter of $A_{i j}$ under target value $P_{j}$. As the optimization value is as small as possible, the optimal value is defined as

$$
F_{j}=\min c_{i j}
$$

The E-REV vehicle lightweight design target is set as $P=\{$ bending rigidity, torsional rigidity, plastic deformation, first bending mode, first torsional mode, weight, and parts price\}. As optimization estimate algorithm, AHP method (AHP is the abbreviation of Analytic Hierarchy Process) is applied in optimization effective factors calculation of E-REV lightweight design. Comparison matrix according to 9-level score standard is described below:

$$
P=\left[\begin{array}{lllllll}
1 & \frac{1}{3} & \frac{1}{2} & \frac{1}{3} & \frac{1}{4} & \frac{1}{5} & \frac{1}{7} \\
3 & 1 & 2 & 1 & \frac{1}{2} & \frac{1}{3} & \frac{1}{5} \\
2 & \frac{1}{2} & 1 & \frac{1}{2} & \frac{1}{3} & \frac{1}{4} & \frac{1}{6} \\
3 & 1 & 2 & 1 & \frac{1}{2} & \frac{1}{3} & \frac{1}{5} \\
4 & 2 & 3 & 2 & 1 & \frac{1}{3} & \frac{1}{4} \\
5 & 3 & 4 & 3 & 3 & 1 & \frac{1}{3} \\
7 & 5 & 6 & 5 & 4 & 3 & 1
\end{array}\right] .
$$

The eigenvector matrix weighted values of different influence factors $W_{i}=$ [plastic deformation, bending rigidity, torsional rigidity, first bending mode, first torsional mode, weight, and parts price $]=\sqrt[n]{\prod_{i=1, j=1}^{n} P_{i j} /\left(\sum_{k=1}^{n} P_{k}^{2}\right)}=$ $[0.031,0.083,0.052,0.083,0.128,0.218,0.405]$. The maximal eigenvalue of matrix is $\lambda_{\max }=\sum\left((P W)_{i} / W_{i}\right) / n=7.213$. The consistency index $\mathrm{CI}=\left(\lambda_{\max }-n\right) /(n-1)=0.036$. By using the methods of table look-up we can know the consistency index $\mathrm{RI}=1.32$ and the consistency ratio $\mathrm{CR}=\mathrm{CI} / \mathrm{RI}<1$. Therefore, the effective factors proportion is rational.

The optimization function can be built considering every effective factor for E-REV lightweight design weighted values:

$$
\begin{gathered}
F\left(M_{i}\right)=\min \left[F_{1}\left(M_{i}\right), F_{2}^{-1}\left(M_{i}\right), F_{3}^{-1}\left(M_{i}\right),\right. \\
F_{4}^{-1}\left(M_{i}\right), F_{5}^{-1}\left(M_{i}\right), \\
\left.F_{6}\left(M_{i}\right), F_{7}\left(M_{i}\right)\right]^{T} W_{i}^{T},
\end{gathered}
$$

where $F_{1}\left(M_{i}\right)$ is plastic deformation and its calculation value is as small as possible. $F_{2}^{-1}\left(M_{i}\right), F_{3}^{-1}\left(M_{i}\right), F_{4}^{-1}\left(M_{i}\right)$, and $F_{5}^{-1}\left(M_{i}\right)$ represent the bending rigidity, the torsional rigidity, the first bending mode, and the first torsional mode. The higher their value is, the better the design is. So take its reciprocal. $F_{6}\left(M_{i}\right)$ and $F_{7}\left(M_{i}\right)$ are the weight and the part prices. Therefore the calculated value should be as small as possible.

The restriction condition can be derived:

$$
\begin{gathered}
F_{1}\left(M_{i}\right)<F_{1}\left(M_{0}\right), \\
F_{i}\left(M_{i}\right)>F_{1}\left(M_{0}\right) ; \quad i=2, \ldots, 5, \\
F_{6}\left(M_{0}\right)-80 \mathrm{~kg}<F_{6}\left(M_{i}\right)<F_{6}\left(M_{0}\right) ; \\
F_{7}\left(M_{0}\right)-30 \text { thousand yuan }<F_{7}\left(M_{i}\right)<F_{7}\left(M_{0}\right),
\end{gathered}
$$

where $\left[F_{1}\left(M_{0}\right), \ldots, F_{7}\left(M_{0}\right)\right]^{T}$ are the optimization target default values. According to the prototype test data, the default values are $\left[35 \mathrm{~mm}, 28000 \mathrm{~N} / \mathrm{mm}, 19000 \mathrm{~N} \cdot \mathrm{m} /{ }^{\circ}, 45 \mathrm{~Hz}\right.$, $40 \mathrm{~Hz}, 1900 \mathrm{~kg}, ¥ 80,000]$. The maximized reduction of the vehicle body weight and the part prices are $80 \mathrm{~kg}$ and $¥ 30,000$, respectively (approximately $\$ 5,000$ ). In order to reduce the calculating workload, the relationship between the whole part prices and the part weight is presented and solved by the linear curve.

Compared with the prototype vehicle, the front floor, the central floor, the roof cover, the threshold, and the central 
channel stiffener are not changed much, while the vehicle rear floor, the rear stringer, and the side hoarding have been strengthened. Compared with the prototype vehicle, the whole weight of E-REV before lightweight adds $5.206 \mathrm{~kg}$. The weight of the rear floor and the rear beam has been increased about $2.5 \mathrm{~kg}$. Based on the previous experiences, the affected parts are usually the BIW rear floor, the rear beam, the spare pool, and the rear stringer.

The weight of the parts is $0.5 \mathrm{~kg}$ when simplifying the optimization calculation process and accelerating the computation speed. The thicknesses of the 70 parts which are taken as the optimization targets are input the formula (4), and then calculate and gain the 4 optimal results by 91 iterations.

The weight of optimal point influential factors after standardization $W_{0}=[0.051,0.372,0.042,0.383,0.115,0.481$, $0.324]$, while the optimal result $F_{0}(M)=[35.4 \mathrm{~mm}, 28146 \mathrm{~N} /$ $\left.\mathrm{mm}, 18235 \mathrm{Nm} /{ }^{\circ}, 43.6 \mathrm{~Hz}, 42.8 \mathrm{~Hz}, 1878 \mathrm{~kg}, ¥ 67,000\right]$.

According to the actual situation, the optimal results need to be adjusted again. However, according to the analysis and the calculating results, the part weight has a great influence on lightweight design and part price. Therefore, to control the part weight and the thickness is the most effective method for E-REV lightweight.

Based on the previous experiences, the two effective methods of reducing parts weight are to reduce the thickness of parts and to use high strength steel under the condition of keeping parts performance.

Suppose the thickness of steel is $t$ and width is $w$; the face maximal stress of plate without damage is defined as

$$
P_{\max }=w t \sigma_{y}
$$

where $w$ and $t$ are the width and thickness of plate and $\sigma_{y}$ is the yield stress. If steel was changed by high strength steel, plate thickness with no plastic deformation is defined as

$$
t^{\prime}=\frac{t \sigma_{y}}{\sigma_{y}^{\prime}}
$$

where $\sigma_{y}^{\prime}$ is high strength plate yield stress. Similarly, the high strength plate thickness with no plastic bending deformation is described as follows:

$$
t^{\prime}=\frac{t \sqrt{\sigma_{y}}}{\sqrt{\sigma_{y}^{\prime}}}
$$

The manufacturability of complex parts during the lightweight design process needs to be considered. According to the simulation result, reset the weight optimization objective function to make the weight of optimized body structure as close as possible to the performance parameters optimization target, and then the optimization constraints are set. The parts rigidity and mode are the basic static and dynamic performance for traditional vehicle, therefore, setting the rigidity and mode of E-REV optimization constraints, building the weight optimization design program.
TABLE 4: The sensitivity of main parts weight and thickness.

\begin{tabular}{lcccccc}
\hline Variable number & 02 & 03 & 35 & 47 & 55 & 57 \\
\hline Contribution ratio (\%) & 17.3 & 21.1 & 1.23 & 0.91 & 0.87 & 0.63 \\
\hline
\end{tabular}

The weight optimization target function and constraints are given by

$$
\begin{gathered}
F=\min W(X), \\
g_{j}(X) \leq 0, \quad j=1,2, \ldots, m, \\
t_{i \min } \leq t_{i} \leq t_{i \max }, \quad i=1,2, \ldots, n,
\end{gathered}
$$

where $F$ is target function, $W(X)$ is part weight function, $X=\left[\begin{array}{llll}t_{1} & t_{2} & \cdots & t_{n}\end{array}\right]^{T}$ is optimization vector, $t_{i}$ is optimization design part thickness, $t_{i \text { min }}$ and $t_{i \text { max }}$ are optimization design upper limit and lower limit of part thickness, and $g_{j}(X)$ is constraint function.

Set the initial value of the optimization variable into the original thickness of the car body structure parts; $X_{0}$ is the initial optimization vector, and the iteration point is given by

$$
\begin{gathered}
X_{q+1}=X_{q}-q \frac{P \cdot \nabla W\left(X_{q}\right)}{\left\|P \cdot \nabla W\left(X_{q}\right)\right\|}, \\
P=I-G\left[G^{T}-G\right]^{-1} G^{T}, \\
G=\left\lfloor\nabla g_{1}\left(X_{q}\right) \nabla g_{2}\left(X_{q}\right) \Lambda \nabla g_{m}\left(X_{q}\right)\right\rfloor,
\end{gathered}
$$

where $P$ is calculated factor, $I$ is units matrix, and $G$ is the gradient matrix of constraint function. The initial optimization can be gotten from part thickness and the optimization function iterates convergence along negative gradient direction. The optimal value would be gotten in calculated region. The sensitivity of main parts weight and thickness is shown in Table 4.

The number 02 and number 03 variables are the mass of battery pack 1 and battery pack 2 , and number 35 variable is the mass of battery pack 1 mounting bracket, while number 47 variable is the thickness of the upper box. Number 55 and number 57 variables are the thickness of battery pack 2 lower box and cover plate. From the simulation results in Table 4, the weight sensitivity of battery pack 1 and battery pack 2 is the highest. It is obvious that reducing the weight of battery pack 1 and battery pack 2 is a great contribution to the lightweight design. The results of the optimizing calculation are similar to the simulation results. The total weight of battery pack 1 and battery pack 2 is $220 \mathrm{~kg}$, which accounts for $81.5 \%$ proportion of the added weight of E-REV. Therefore, the lightweight of the battery packs and mounting bracket has the greatest influence on E-REV lightweight.

\section{Analysis of E-REV Lightweight Design}

5.1. The Lightweight Design of E-REV. Table 5 shows the bending sensitivity of main parts weight and thickness. Variable number 05 is the weight of charger on left rear 
TABLE 5: The bending sensitivity of main parts weight and thickness.

\begin{tabular}{lcccccc}
\hline $\begin{array}{l}\text { Variable } \\
\text { number }\end{array}$ & 02 & 03 & 05 & 07 & 24 & 46 \\
\hline $\begin{array}{l}\text { Bending rigidity } \\
\text { contribution } \\
\text { ratio (\%) }\end{array}$ & 1.7 & 2.5 & 0.25 & 0.48 & 0.24 & 0.03 \\
$\begin{array}{l}\text { Torsional } \\
\text { rigidity } \\
\begin{array}{l}\text { contribution } \\
\text { ratio (\%) }\end{array}\end{array}$ & 0.9 & 1.1 & 0.11 & 0.09 & 0.07 & 0.02 \\
\hline
\end{tabular}

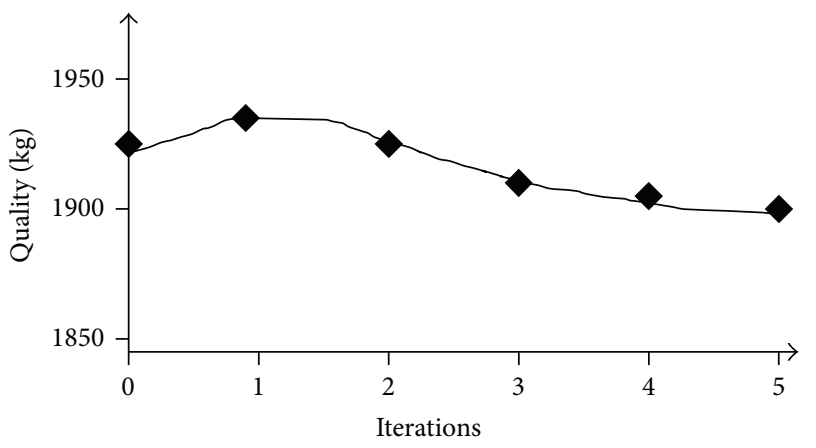

FIGURE 5: The simulation result of vehicle weight.

stringer, variable number 07 is the weight of drive motor on rear drive shaft, variable number 24 is the weight of leadacid battery, and variable number 46 is the thickness of charger mounting bracket. According to the analysis results in Table 5, the weight and thickness of the main parts have little influence on bending sensitivity [14].

The parts' optimized thickness and the result of the optimized objective function are shown in Figure 5; the vehicle weight reduces from $1935 \mathrm{~kg}$ to $1861 \mathrm{~kg}$. However, according to the actual steel plate standard, the optimized thickness should be adjusted again.

According to (8), the Q235 (yield stress is $215 \mathrm{MPa}$ ) steel sheet of the primary battery box is changed into the high strength steel sheet (yield stress is $410 \mathrm{MPa}$ ). The thickness $t=2.0 \mathrm{~mm}$ of Q235 sheet is reduced to the thickness $t^{\prime}=$ $1.448 \mathrm{~mm}$ of the new high strength steel sheet under the circumstance of the plastic deformation not occurring.

According to the simulation analysis, the weight loss results of main parts are shown in Table 6.

If the large capacity batteries are used, then total battery voltage drops from $352 \mathrm{~V}$ to $320 \mathrm{~V}$ and the total weight of the batteries reduces by $28.78 \mathrm{~kg}$ based on the constant total battery energy. In this case, the lightweight proportion is $13.08 \%$ and the lightweight effect is obvious.

In order to guarantee the strength and rigidity of the important loaded components during car body lightweighting design, the shape of some parts is changed from opening shape to closed shape. Then the thickness of those parts can be reduced and the strength and rigidity of those parts are greatly improved without added weight [15].

The lightweight of the fixed structure of the E-REV body is also designed. The thickness of the plate sheet reduces from
TABLE 6: Weight loss comparison of main parts in battery pack.

\begin{tabular}{lccc}
\hline Parts & $\begin{array}{c}\text { Thickness } \\
(\mathrm{mm})\end{array}$ & $\begin{array}{c}\text { Lightweight } \\
\text { thickness } \\
(\mathrm{mm})\end{array}$ & $\begin{array}{c}\text { Reducing } \\
\text { weight }(\mathrm{kg})\end{array}$ \\
\hline $\begin{array}{l}\text { Battery pack 1 } \\
\text { upper box } \\
\text { Battery pack 1 } \\
\text { low box } \\
\text { Battery pack 1 } \\
\text { mounting }\end{array}$ & 2.0 & 1.0 & 2.28 \\
$\begin{array}{l}\text { bracket } \\
\text { Battery pack 2 } \\
\text { cover }\end{array}$ & 2.0 & 1.5 & 0.186 \\
$\begin{array}{l}\text { Battery pack 2 } \\
\text { low box }\end{array}$ & 2.0 & 1.5 & 0.22 \\
\hline
\end{tabular}

TABLE 7: The rear-end collision simulation comparison of E-REV before and after lightweighting the main parts.

\begin{tabular}{lccc}
\hline & $\begin{array}{c}\text { Before } \\
\text { lightweight } \\
(\mathrm{mm})\end{array}$ & $\begin{array}{c}\text { After } \\
\text { lightweight } \\
(\mathrm{mm})\end{array}$ & $\begin{array}{c}\text { Difference } \\
(\%)\end{array}$ \\
\hline $\begin{array}{l}\text { Maximal } \\
\text { deformation of } \\
\text { vehicle body }\end{array}$ & 350 & 344 & 1.7 \\
$\begin{array}{l}\text { Maximal } \\
\text { deformation of }\end{array}$ & 31 & 22 & 29 \\
$\begin{array}{l}\text { battery pack 1 } \\
\text { Maximal } \\
\text { deformation of }\end{array}$ & 14.1 & 13.8 & 1.4 \\
$\begin{array}{l}\text { battery pack 1 } \\
\text { mounting bracket }\end{array}$ & & & \\
$\begin{array}{l}\text { Maximal } \\
\text { deformation of } \\
\text { battery pack 2 }\end{array}$ & 35 & 27.8 & 20.6 \\
$\begin{array}{l}\text { Maximal } \\
\text { deformation of } \\
\text { battery pack 2 } \\
\text { mounting bracket }\end{array}$ & 26.7 & & \\
\hline
\end{tabular}

$2.0 \mathrm{~mm}$ to $1.5 \mathrm{~mm}$ and the total weight of the car body reduces by $37.62 \mathrm{~kg}$, the proportion of weight loss is $13.9 \%$, and the total vehicle weight after lightweight is $1868.68 \mathrm{~kg}$. The results agree well with the optimization function calculated results and the lightweight effect is obvious.

5.2. The Rear-End Collision Simulation of E-REV after Lightweight. The lightweight FEM model of E-REV is input again and is calculated. From the simulation result, the mounting bracket of battery pack 1 is impacted and the deformation process and the time of appearing maximal acceleration are similar to before. It explains that energy absorption capability of battery pack 1 mounting bracket does not drop after lightweight design. The crash force is close to the crash force before lightweight under rear-end collision test. The rear-end collision simulation comparison of E-REV before and after weight loss of main parts is shown in Table 7. 
TABLE 8: The mode simulation of E-REV before and after lightweighting the main parts.

\begin{tabular}{lcc}
\hline & Bending mode $(\mathrm{Hz})$ & Torsional mode $(\mathrm{Hz})$ \\
\hline Before lightweight & 44.5 & 38.3 \\
After lightweight & 43.7 & 42.4 \\
\hline
\end{tabular}

To some extent, the maximal deformations of two battery packs' mounting brackets drop and the box structures are strengthened after the lightweight design as shown in Table 7. The collision protection of the battery packs has strengthened and then the electric shock risk will be reduced because the risk of the battery module damage and electrolyte leakage is largely reduced. The results are very important for passing standards GB 20072 and GB/T 19751 during the rear-end collision test of E-REV.

The mode simulation results of E-REV are shown in Table 8 . The simulation results are based on the complete BIW (body in white) with dormer, front subframe, and front and rear windshield. They show that the first-order bending mode of E-REV after lightweight is close to the result before lightweight and the torsional modal frequency greatly improved. Similarly, they can predict that rigidity of E-REV BIW after lightweight is close to the result before lightweight.

As the lightweight model has passed rear-end collision test, it can be predicted that the E-REV after lightweight will get better experimental results and pass the rear-end collision test.

\section{The Rear-End Collision Test of E-REV after Lightweight}

The rear-end collision test of lightweight E-REV operates according to standard GB 20072-2006. The collision speed is $50 \pm 2 \mathrm{~km} / \mathrm{h}$ and fuel is replaced by water before the test.

The collision acceleration curves of battery pack 1 bracket under rear-end collision test before and after weight loss of main parts are shown in Figure 6. Compared with the simulation, the peak acceleration and appearing time have some deviation, but the acceleration curves are coincident. All the curve trends are similar and the discrepancy is very little $(<10 \%)$ at the maximal acceleration happen time; then the test data show that the simulation model is accurate and can be used to analyze the rear-end collision safety of E-REV.

Figure 7 is the knocked-down picture of E-REV battery pack 1 and battery pack 2 under rear-end collision test after weight loss of main parts. As shown in Figure 7(a), the battery mounting bracket deforms, but the deformation is not large and the battery module of the battery pack 1 is not obviously damaged. So the battery mounting bracket plays an important role in resisting deformation and energy absorption. After rear-end collision test, the left-front module bracket of the battery pack 2 has a little deformation, but bolt, cable, harness, and connection are not damaged. The bakelite plate is broken but with no battery damage and leak, as shown in Figure 7(b). It is found that the voltages of three battery modules are abnormal in battery pack 2 , but the voltages of other battery modules in battery pack 1 and battery pack 2 are normal.

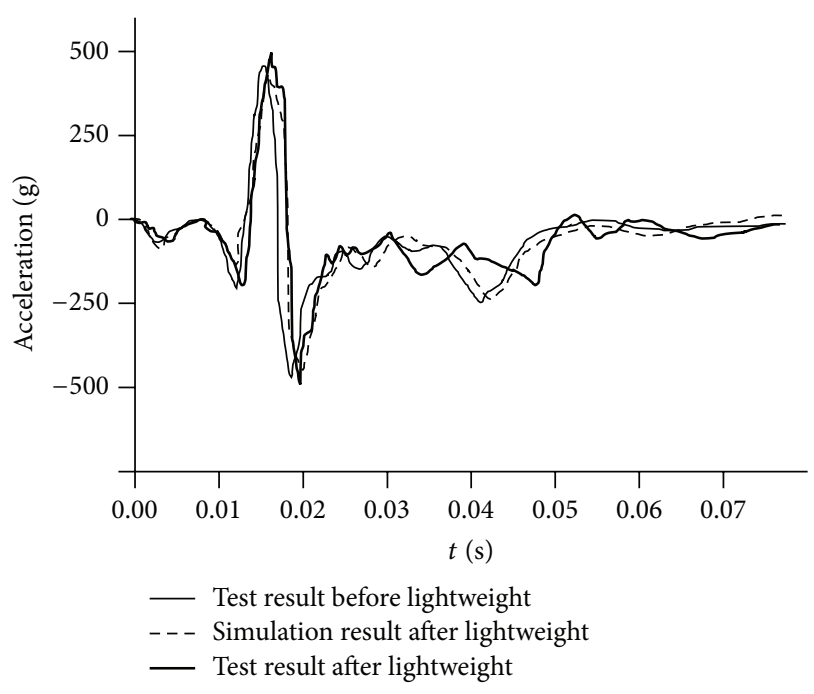

FIGURE 6: The collision acceleration of battery pack 1 bracket under rear-end collision test before and after lightweighting the main parts.

TABLE 9: The test result of E-REV vehicle modality after lightweighting the main parts.

\begin{tabular}{lccc}
\hline & Test & Simulation & Deviation \\
\hline Torsional mode $(\mathrm{Hz})$ & 41.3 & 42.4 & $2.66 \%$ \\
Bending mode $(\mathrm{Hz})$ & $42.9 \mathrm{~Hz}$ & 43.7 & $1.86 \%$ \\
\hline
\end{tabular}

The experimental results can pass the requirement of standard GB/T 19751.

The simulation results of the maximal vibration displacement under rear-end collision test after lightweighting the main parts can be shown in Figure 8. The locations of the maximal vibration displacement and bending displacement are consistent with the test results. The rear-crash test method is done according to the test process in GB 20072.

The test results of E-REV vehicle modality after weight loss of main parts are given in Table 9. They draw a conclusion that they are similar to simulation result of torsional and bending modal after lightweight. The reliability of simulation model and theory analysis is proved to be right from data in Table 9. The BIW mode of E-REV after weight loss of main parts is similar to before.

The deviation of battery pack 1 maximal deformation simulation compared with test data reaches to $15.7 \%$, but other parts' maximal deformation simulation deviation is accurate and less than $10 \%$. On the other hand, it demonstrates that the simulation model is reliable. The comparison data are given in Table 10.

The rear-end collision test of E-REV completely satisfied standards GB/T 19751-2005 (hybrid electric vehicles safety specification) and GB 20072-2006 (the requirements of fuel system safety in the event of rear-end collision for passenger car) $[16,17]$. 


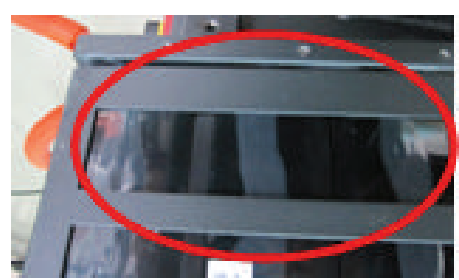

(a) Deformation of battery pack 1

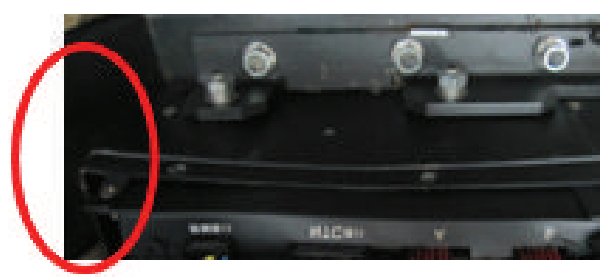

(b) Deformation of battery pack 2

Figure 7: The knocked-down picture of E-REV battery pack 1 and battery pack 2 under rear-end collision test after lightweighting the main parts.

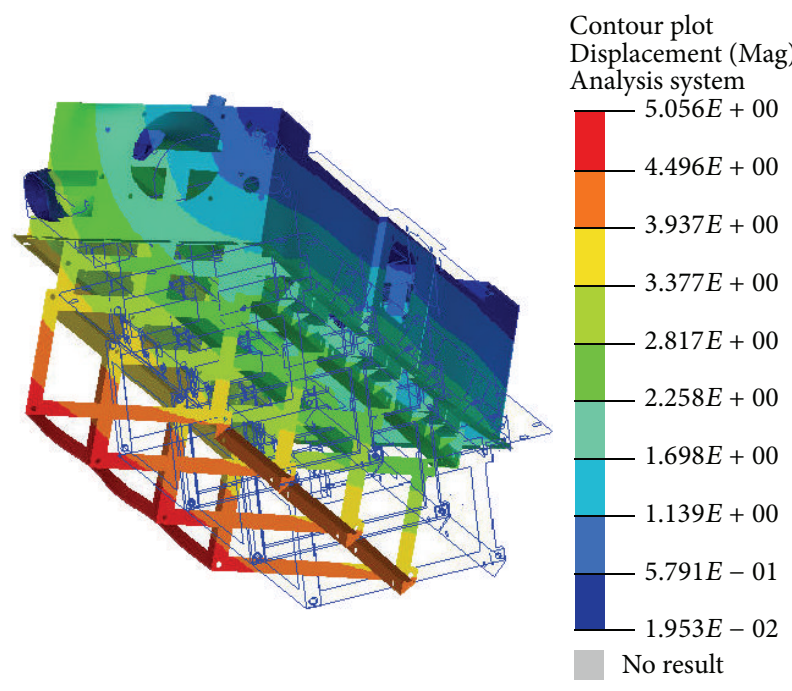

FIGURE 8: The deformation comparison of simulation picture of EREV battery pack 1 inner structure under rear-end collision test after lightweighting the main parts.

\section{Conclusions}

The total mass of E-REV is heavier than the prototype vehicle. In view of the massive influence of the total mass of E-REV on fuel economy and passive safety, the lightweight design of EREV is analyzed and the optimized objective function is built based on the rear-end collision safety. The influence factor and weight sensitivity of E-REV lightweight design are analyzed. According to the simulation results, the battery pack structures and the battery pack mounting brackets are mainly lightweight objects to be optimized to drop E-REV weight. It is proved that the total mass of E-REV is cut down largely under the precondition of enough passive safety. So the fuel economy and emission of the vehicle are improved largely after lightweight. It is proved that E-REV has enough safety by rational lightweight optimization methods from the rear-end collision results of the simulation and test. It can effectively reduce the weight of key parts using the high strength and light materials under the precondition of crash safety and manufacturing cost control by the optimization design. The multitarget optimization function is an important method for lightweight. The results show that the lightweight design method is effective and the simulation model is correct. It
TABLE 10: The rear-end collision test of E-REV after lightweighting the main parts.

\begin{tabular}{|c|c|c|c|}
\hline & Test & Simulation & Deviation \\
\hline $\begin{array}{l}\text { Maximal } \\
\text { deformation of } \\
\text { vehicle body }(\mathrm{mm})\end{array}$ & 341 & 344 & $1.7 \%$ \\
\hline $\begin{array}{l}\text { Maximal } \\
\text { deformation of } \\
\text { battery pack } 1 \\
(\mathrm{~mm})\end{array}$ & 19 & 22 & $15.7 \%$ \\
\hline $\begin{array}{l}\text { Maximal } \\
\text { deformation of } \\
\text { battery pack } 1 \\
\text { mounting bracket } \\
(\mathrm{mm})\end{array}$ & 14 & 13.8 & $1.43 \%$ \\
\hline $\begin{array}{l}\text { Maximal } \\
\text { deformation of } \\
\text { battery pack } 2 \\
(\mathrm{~mm})\end{array}$ & 28 & 27.8 & $0.7 \%$ \\
\hline $\begin{array}{l}\text { Maximal } \\
\text { deformation of } \\
\text { battery pack } 2 \\
\text { mounting bracket } \\
(\mathrm{mm})\end{array}$ & 24 & 25.3 & $5.4 \%$ \\
\hline
\end{tabular}

is possible to analyze other similar lightweight problems of new energy vehicles by the similar simulation model and optimization methods.

\section{Conflict of Interests}

The authors declare that there is no conflict of interests regarding the publication of this paper.

\section{Acknowledgment}

The authors are grateful to the support from the National Natural Science Foundation of China (no. 51475336).

\section{References}

[1] E. Baker, "Option value and the diffusion of energy efficient products," Energy Journal, vol. 33, no. 4, pp. 49-59, 2012.

[2] J. Hirsch and T. Al-Samman, "Superior light metals by texture engineering: optimized aluminum and magnesium alloys for 
automotive applications," Acta Materialia, vol. 61, no. 3, pp. 818843, 2013.

[3] R. Wolf, "Rolled aluminium surface preparation for packaging applications," Aluminium International Today, vol. 19, no. 4, pp. 36-40, 2007.

[4] L. Case, "A new lightweight aluminum wheel manufacturing technology is capturing business from OEMs," Automotive Industries, vol. 188, no. 7, p. 3, 2008.

[5] K. L. Calvert, J. Griffioen, and S. Wen, "Scalable network management using lightweight programmable network services," Journal of Network and Systems Management, vol. 14, no. 1, pp. 15-47, 2006.

[6] J. J. del Coz Díaz, P. J. García Nieto, J. Domínguez Hernández, and A. Suárez Sánchez, "Thermal design optimization of lightweight concrete blocks for internal one-way spanning slabs floors by FEM," Energy and Buildings, vol. 41, no. 12, pp. 12761287, 2009.

[7] J. B. Cardoso, P. P. Moita, and A. J. Valido, "Design and control of nonlinear mechanical systems for minimum time," Shock \& Vibration, vol. 15, no. 3-4, pp. 315-323, 2008.

[8] J. Ribau, C. Silva, F. P. Brito, and J. Martins, "Analysis of fourstroke, Wankel, and microturbine based range extenders for electric vehicles," Energy Conversion and Management, vol. 58, pp. 120-133, 2012.

[9] Chinese Standards, "Seat and seat fastness equipment and pillow intension requirements and test method," GB/T 150832006, 2006.

[10] D. Lu and C. Cai, "Identification of dynamic vehicular axle loads: theory and simulations," Journal of Vibration and Control, vol. 16, no. 14, pp. 2167-2194, 2010.

[11] C. S. Chin, "Shock analysis method for systematic performance evaluation of component embedded in handheld electronic devices," Shock \& Vibration, vol. 13, no. 6, pp. 607-618, 2006.

[12] J. Cho and U. Lee, "An FFT-based spectral analysis method for linear discrete dynamic systems with non-proportional damping," Shock \& Vibration, vol. 13, no. 6, pp. 595-606, 2006.

[13] S.-E. Fang and R. Perera, "Damage identification by response surface based model updating using D-optimal design," Mechanical Systems and Signal Processing, vol. 25, no. 2, pp. 717733, 2011.

[14] D. Wesemeier and R. Isermann, "Identification of vehicle parameters using stationary driving maneuvers," Control Engineering Practice, vol. 17, no. 12, pp. 1426-1431, 2009.

[15] M. Rozyn and N. Zhang, "A method for estimation of vehicle inertial parameters," Vehicle System Dynamics, vol. 48, no. 5, pp. 547-565, 2010.

[16] GB/T 19751-2005, Hybrid electric vehicles safety specification, 2006.

[17] GB 20072-2006, “The requirements of fuel system safety in the event of rear-end collision for passenger car," 2006. 

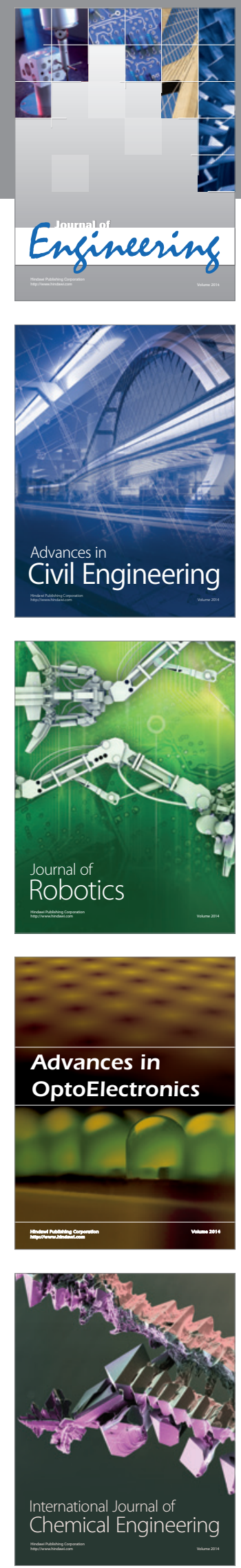

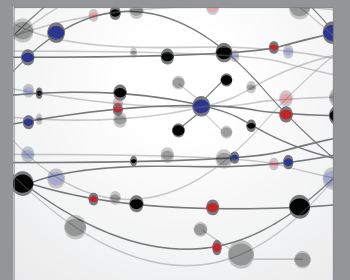

The Scientific World Journal
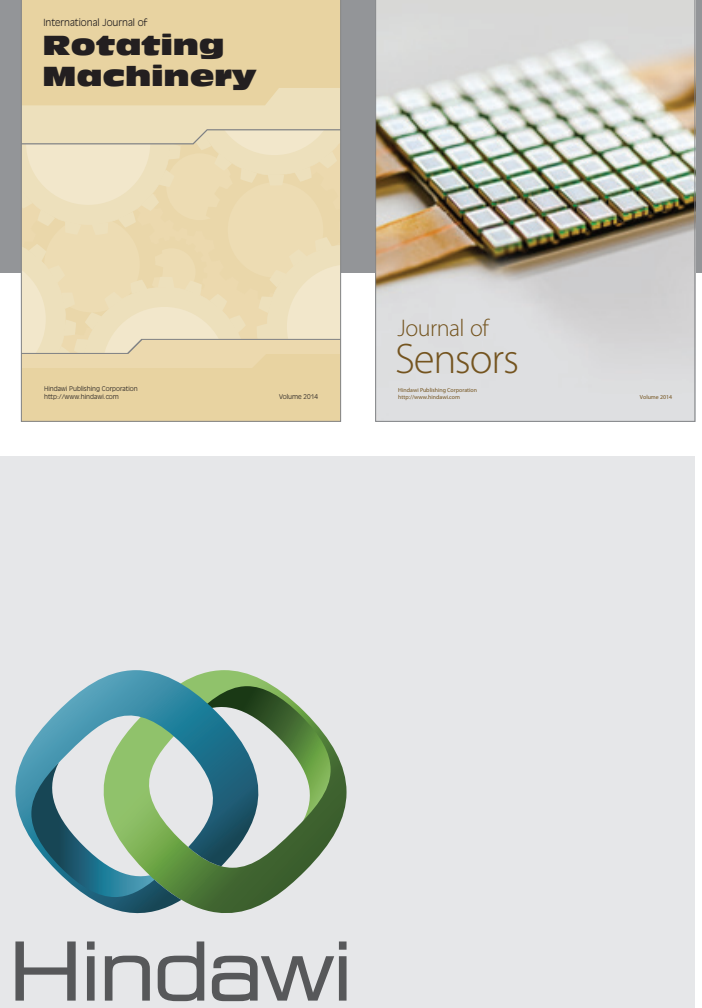

Submit your manuscripts at http://www.hindawi.com
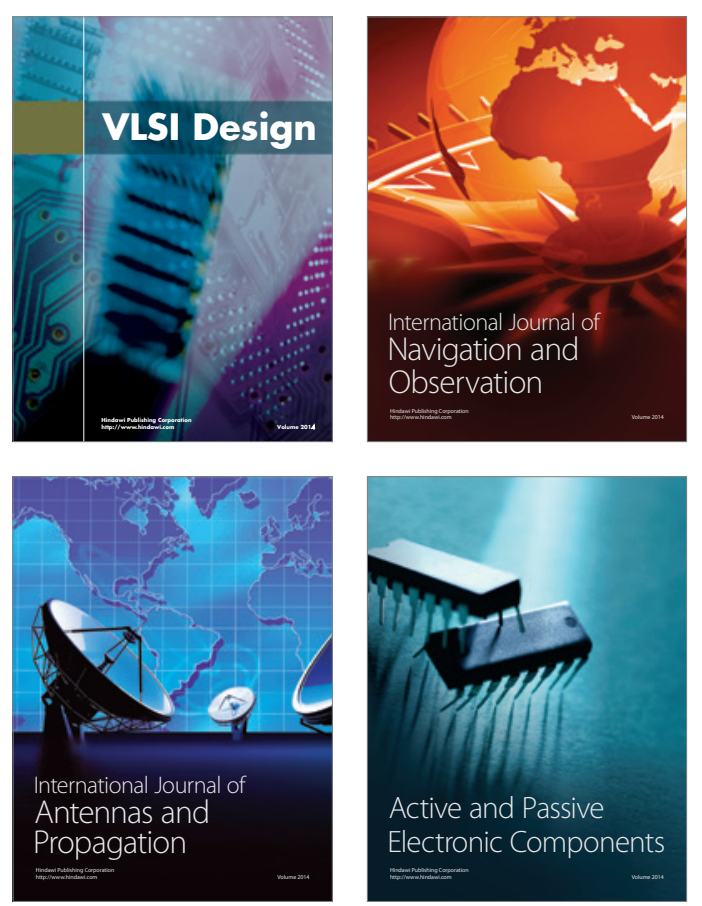
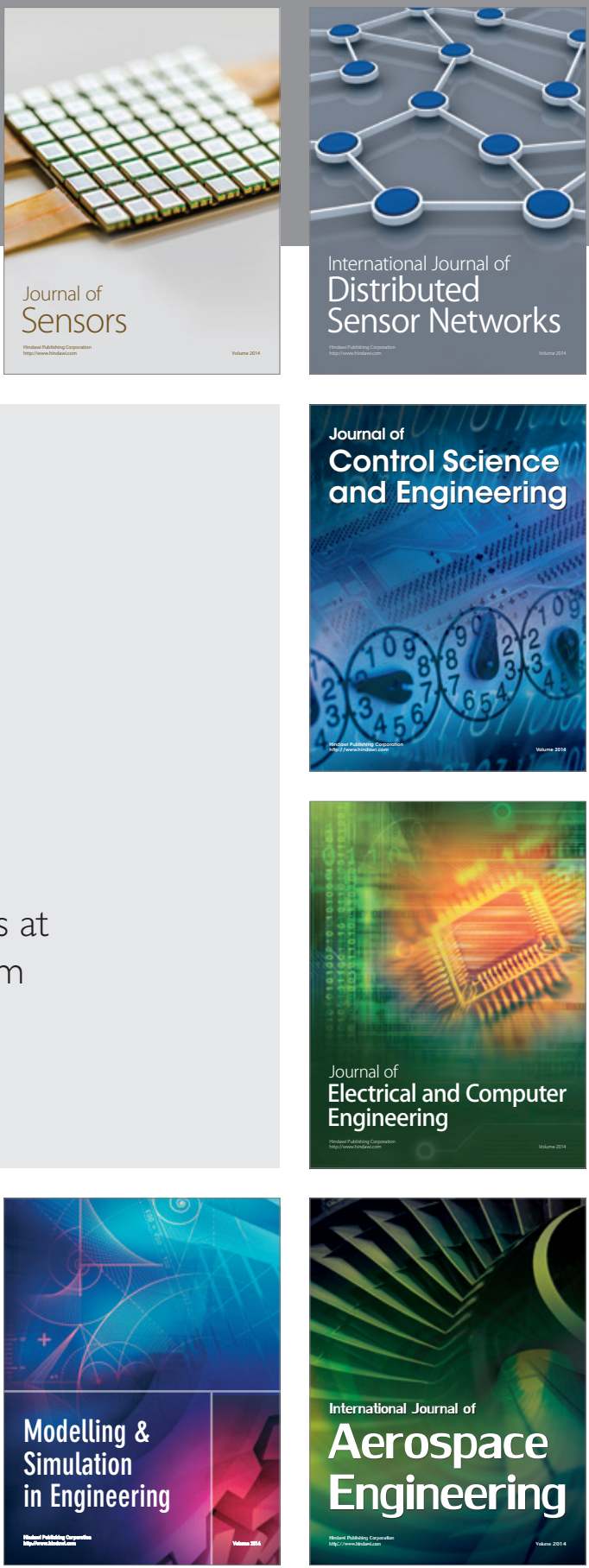

Journal of

Control Science

and Engineering
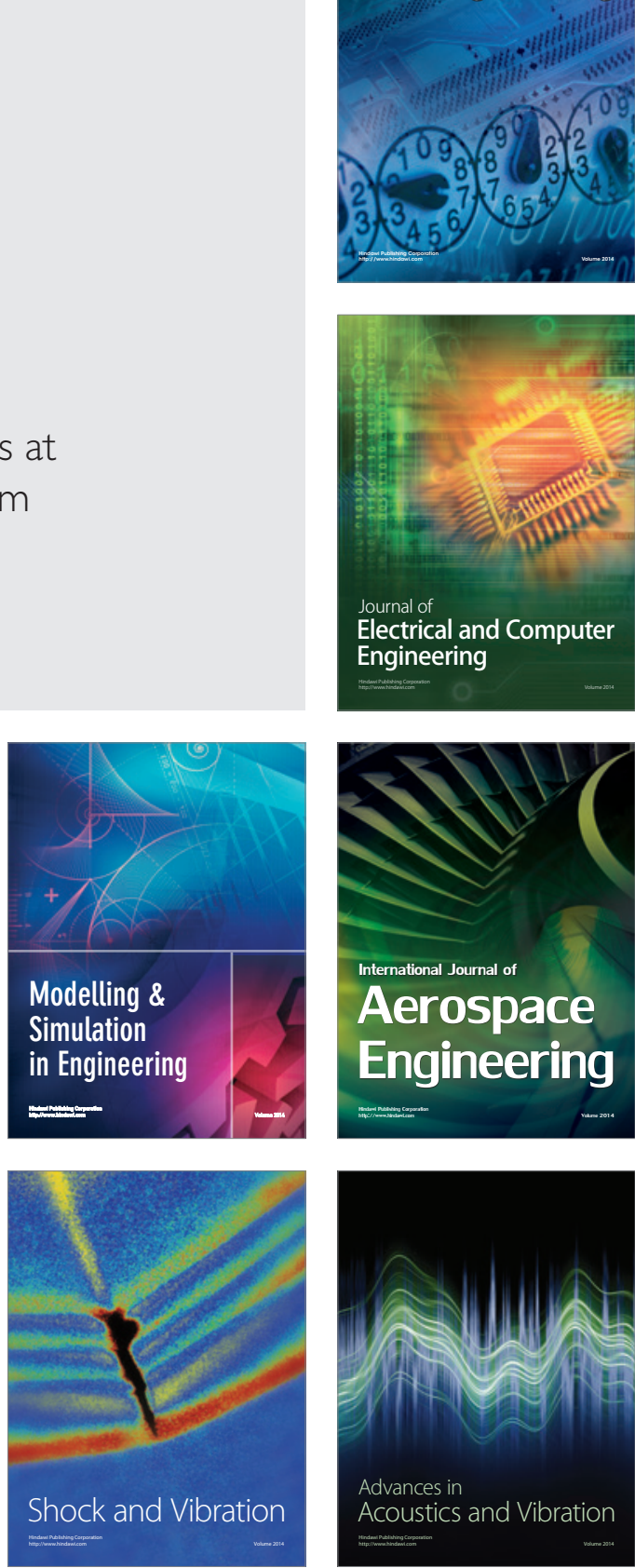